\title{
SENSITIVITY OF THE GENUS PROTEUS TO CHLORHEXIDINE
}

\author{
T. D. M. MARTIN \\ Department of Pathology, Royal Berkshire Hospital, Reading
}

THE widely used antiseptic, chlorhexidine, is generally believed to possess high activity against most of the human pathogens with which it is required to contend; and although its activity against Gram-negative organisms is less than that against Gram-positive ones, it is still in excess of what is required in actual practice (Davies et al., 1954; Lawrence, 1960).

It has been claimed, however (Lubsen, Boissevain and Fass, 1961), that the resistance to chlorhexidine of some proteus strains is sufficiently high to be of clinical significance. These workers found, moreover, that one species, Proteus rettgeri, was particularly resistant, and suggested that an increase of Pr. rettgeri infections in their urological ward was connected with the use of this antiseptic. These claims were criticised by Beeuwkes (1961), who repeated the in-vitro testing of some of the proteus strains of Lubsen et al. and failed to confirm the degree of chlorhexidine-resistance.

In view of the widespread use of chlorhexidine and the prevalence of proteus infections of the urinary tract, particularly in hospitals, this question is of obvious interest. A number of strains of different species of the Proteus group, isolated during the course of routine hospital bacteriology, have therefore been tested against various concentrations of the antiseptic.

The sensitivity of the same strains to a number of chemotherapeutic drugs was also tested, primarily to determine whether chlorhexidine-resistance was associated with " hospital strains" of Proteus, i.e., those showing multiple drug-resistance.

\section{MATERIALS AND METHODS}

Source of strains

The 205 strains of Proteus studied were isolated during the routine examination of specimens from hospital in-patients and out-patients, and from the patients of general practitioners: 162 strains were isolated from urines and 43 from other sources, mainly wound swabs. No strains from faeces were included.

Gram-negative bacilli that swarmed on blood agar and had a urinous smell, or produced urease in the course of routine laboratory screening tests, were purified by plating on MacConkey's agar. A single colony was then placed on a nutrient agar slope. After incubation the slopes were stored at room temperature.

\section{Biochemical tests}

Incubation was at $37^{\circ} \mathrm{C}$ throughout, except in the case of gelatin cultures.

Phenylalanine deaminase was detected by growing the organisms on phenylalanine agar

Received 24 Aug. 1968; accepted 1 Oct. 1968.

J. MED. MICROBIOL.-VOL. 2 (1969) 
(Edwards and Ewing, 1962) and testing with 10 per cent. ferric chloride after incubation overnight.

Urease production was tested on Christensen's medium.

Decarboxylase tests. Falkow's modification (Falkow, 1958) of Møller's medium (Møller, 1955) was used. Falkow described his medium as for the detection of lysine decarboxylase only, but Edwards and Ewing state that it can also be used successfully with arginine and ornithine in most areas of the family Enterobacteriaceae, although not with Klebsiella and Aerobacter. The tests were read after 3 days' incubation.

Indole production. This was tested with Kovacs' reagent on peptone water cultures after 24 and 48 hours' incubation.

Hydrogen sulphide production. Dried lead acetate papers were suspended over freshly inoculated peptone water cultures and read after incubation overnight.

Citrate utilisation. Simmons' citrate agar was inoculated with a straight wire from a peptone water culture and read after 3 days' incubation.

Gelatin liquefaction. Stab cultures were kept at room temperature for up to $3 \mathrm{wk}$.

Carbohydrate fermentation. Cultures in peptone water " sugars" containing Andrade's indicator were incubated for 7 days.

\section{Chlorhexidine-sensitivity tests}

From 20 per cent. chlorhexidine digluconate, dilutions of 1 in 10,000, 1 in 20,000 and 1 in 40,000 were made in $1 \mathrm{ml}$ volumes of broth (Oxoid Nutrient Broth no. 2) in $7.5 \times 1 \mathrm{~cm}$ tubes. A standard loopful of a 24-hr culture of the strain to be tested was inoculated into each tube. The tubes were incubated at $37^{\circ} \mathrm{C}$ and observed at 24 and $48 \mathrm{hr}$ for signs of growth.

After 48 hours' incubation, bactericidal activity was examined by subculturing one loopful from each tube that showed no growth to a quarter of a blood agar plate in which transverse ditches had been cut. The suggestion of Beeuwkes and Lubsen et al. was followed, and no chlorhexidine inhibitor was added to the agar.

\section{Drug-sensitivity tests}

These were done by a disk-plate method. Just sufficient of the test strain to make the medium faintly opalescent was inoculated into $5 \mathrm{ml}$ of broth and incubated for 4-5 hr. One drop of this culture was then added to $5 \mathrm{ml}$ of broth and the resulting suspension used to flood an agar plate (Oxoid Diagnostic Sensitivity Test Base).

The disks used were obtained commercially. Six of the drugs were tested by using a multi-tipped disk with " normal " drug concentrations and another with " high" concentrations. The drugs used and their amounts in micrograms were as follows: ampicillin, 2 and 10 ; streptomycin, 10 and 25; tetracycline, 10 and 50; chloramphenicol, 10 and 50; kanamycin, 5 and 30; nitrofurantoin, 50 and 200.

Single disks or tablets were used for testing nalidixic acid and cephaloridine. One disk only, containing $30 \mu \mathrm{g}$, was used for nalidixic acid. Cephaloridine was tested in the early stages of the study with test tablets containing 1 and $25 \mu \mathrm{g}$. Later this was changed to paper disks containing 5 and $25 \mu \mathrm{g}$.

After overnight incubation, a zone of inhibition with a radius of more than $2 \mathrm{~mm}$ from the edge of the disk was taken to indicate sensitivity to the drug.

\section{RESULTS \\ Identification of species}

All strains submitted to the tests seen in table I had previously been shown to produce phenylalanine deaminase and to be rapid urease producers.

The scheme adopted for the identification of Proteus species was based 
mainly on the work of Edwards and Ewing (1962). One difference is that with the triple sugar iron agar used by these authors to detect hydrogen sulphide production $P r$. morganii gives a negative result; with lead acetate papers the result is usually positive.

It will be seen that the tests are divided into two sets. All strains were tested with the first set initially, and any strain that gave the results listed in table I for a particular species was assigned to that species without further testing. Only those strains that were aberrant in one or more characteristics in the first set were subjected to the second set of tests before their species was decided.

\section{TABLE I}

Tests used in identification of Proteus species and results with typical strains

\begin{tabular}{|c|c|c|c|c|}
\hline Species & Pr. mirabilis & Pr. rettgeri & Pr. vulgaris & Pr. morganii \\
\hline $\begin{array}{l}\text { Primary tests } \\
\text { Maltose } \\
\text { Mannitol } \\
\text { Arginine } \\
\text { Lysine } \\
\text { Ornithine } \\
\text { Indole } \\
\text { Gelatinase } \\
\mathrm{H}_{2} \mathrm{~S} \text { production }\end{array}$ & $\begin{array}{l}- \\
- \\
- \\
- \\
+ \\
\frac{+}{+} \\
+\end{array}$ & $\begin{array}{l}\overline{ \pm} \\
\pm \\
\overline{-} \\
\pm \\
\pm \\
-\end{array}$ & $\begin{array}{l}+ \\
- \\
- \\
- \\
- \\
+ \\
+ \\
+\end{array}$ & $\begin{array}{l}- \\
- \\
\overline{-} \\
+ \\
+ \\
+ \\
+\end{array}$ \\
\hline $\begin{array}{l}\text { Secondary tests } \\
\text { Sucrose } \cdot \\
\text { Salicin }: \\
\text { Xylose }: \\
\text { Adonitol } \\
\text { Inositol } \\
\text { Simmons' citrate }\end{array}$ & $\begin{array}{c}+ \text { or }(+) \\
\text { d } \\
+ \\
- \\
- \\
+\end{array}$ & $\begin{array}{l}\mathrm{d} \\
\mathrm{d} \\
\mathrm{d} \\
+ \\
+ \\
+\end{array}$ & $\begin{array}{l}+ \\
d \\
d \\
- \\
d\end{array}$ & $\begin{array}{l}\frac{d}{-} \\
- \\
- \\
-\end{array}$ \\
\hline No. of strains tested & 126 & 36 & 27 & 16 \\
\hline
\end{tabular}

$+=$ Positive result $;-=$ negative result $;(+)=$ late positive; $d=$ different reactions. All strains produced phenylalanine deaminase and urease.

In practice, it was found that the majority of strains of Pr. mirabilis, Pr. rettgeri and Pr. morganii could be identified with the first set of tests.

In the case of $P r$. vulgaris, however, of the 27 strains isolated, 8 (all of them from in-patients) were indole-negative. Previous workers (Dutton and Ralston, 1957; Kippax, 1957; Milner, 1963) have shown that Pr. vulgaris infections in hospital patients may commonly be due to indole-negative strains, and this characteristic has been used as a marker to demonstrate cross-infection. It is of interest, therefore, that 4 of the present 8 strains came from patients in the same ward.

Only 1 of the 8 strains fermented xylose, in contrast with the indole-negative strains described by Kippax and by Milner, which were all xylose-positive; otherwise their biochemical reactions were similar. 


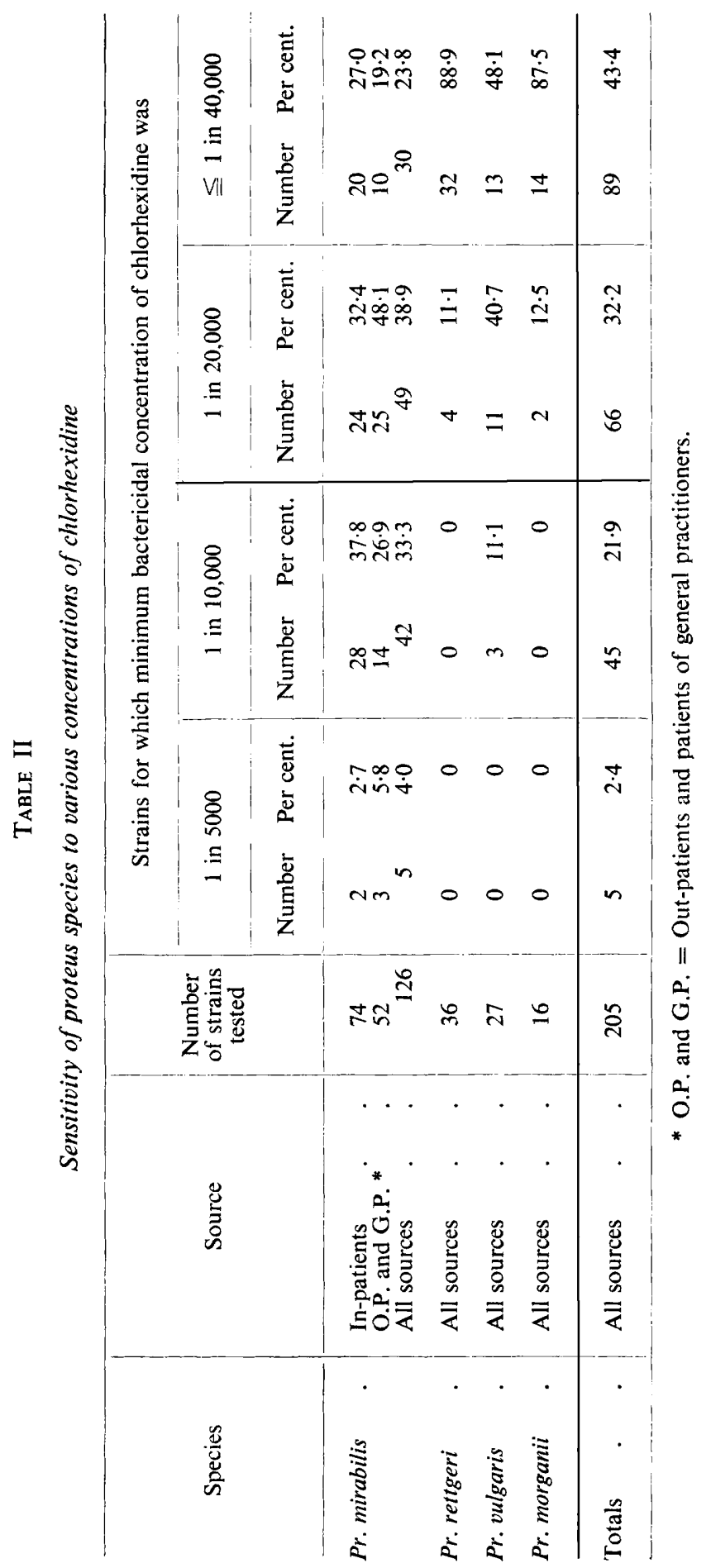




\section{Sensitivity of Proteus species to chlorhexidine}

The sensitivity of the four species of Proteus to chlorhexidine, under the conditions of the test described under Materials and methods, is shown in table II. Only three concentrations were used as a routine-1 in 10,000 , 1 in 20,000 and 1 in 40,000 -since few strains were expected to survive 1 in 10,000, and dilutions of more than 1 in 40,000 are unlikely to be used in practice. The few strains that survived chlorhexidine 1 in 10,000 were re-tested with a concentration of 1 in 5000 .

None of the total of 205 strains survived a concentration of 1 in 5000 chlorhexidine, and only 5 a concentration of 1 in 10,000. All 5 strains were of the same species-Pr. mirabilis-and one-third of the strains of that species were able to survive 1 in 20,000 .

By contrast, not only was no strain of Pr. rettgeri able to survive the higher concentrations, but nearly 90 per cent. of these strains were killed by a concentration of 1 in 40,000. Moreover, since this was the lowest concentration tested, the minimum bactericidal concentration may well have been less.

Relatively few strains of Pr. morganii were isolated, but it will be seen that the results with these were almost identical with those obtained with Pr. rettgeri.

The 27 strains of Pr. vulgaris tested showed for the most part an intermediate degree of chlorhexidine-sensitivity.

The minimum bacteriostatic concentrations were, in the great majority of cases, close to the minimum bactericidal ones. Of the 5 strains that survived chlorhexidine 1 in 10,000, one grew in 1 in 20,000; growth was inhibited by 1 in 10,000, but the effect was bacteriostatic only; a concentration of 1 in 5000 proved bactericidal. The remaining 4 strains all grew in a concentration of 1 in 10,000 , but were killed by 1 in 5000 .

\section{Chlorhexidine-sensitivity of Pr. mirabilis related to drug-sensitivity}

All proteus strains tested against chlorhexidine were also tested against a number of chemotherapeutic drugs, to determine whether resistance to one was associated with resistance to the other.

However, since no strains of Pr. rettgeri or Pr. morganii, and only 3 strains of Pr. vulgaris, were resistant to more than 1 in 20,000 chlorhexidine, there seemed little point in comparing these 3 species in this way; and Pr. mirabilis strains, therefore, are the only ones to be so considered.

All proteus strains were tested against 8 drugs, as described under Materials and methods, using " normal " and " high" concentrations, except in the case of nalidixic acid where only one concentration was available. The drugs were: ampicillin, streptomycin, tetracycline, chloramphenicol, kanamycin, nitrofurantoin, cephaloridine and nalidixic acid.

A comparison of drug- and chlorhexidine-sensitivity of Pr. mirabilis is shown in table III, where the strains have been divided into those resistant to 3 drugs or fewer, and those resistant to 4 drugs or more. No strain of 
Pr. mirabilis was resistant to more than 6 of the drugs, since all strains of this species were sensitive to cephaloridine and nalidixic acid. It may be of some general interest to record that not only were all 126 strains of Pr. mirabilis sensitive to nalidixic acid, but also all 16 strains of Pr. morganii; whilst of the 26 strains of Pr. rettgeri and 27 strains of Pr. vulgaris, only 1 of the former and 3 of the latter were resistant to it.

As expected, almost all strains of Pr. mirabilis were resistant to tetracycline; however, 3 strains were sensitive, and the drug is therefore included among the

TABLE III

Relation of chlorhexidine-sensitivity of Proteus mirabilis to drug-sensitivity

\begin{tabular}{|c|c|c|c|c|c|c|c|}
\hline \multirow{3}{*}{$\begin{array}{l}\text { Source of } \\
\text { strains }\end{array}$} & \multirow{3}{*}{$\begin{array}{l}\text { Drug } \\
\text { concentration } \\
\text { in disks }\end{array}$} & \multirow{3}{*}{$\begin{array}{l}\text { Number of } \\
\text { drugs to which } \\
\text { resistant }\end{array}$} & \multirow{3}{*}{$\begin{array}{l}\text { Number } \\
\text { of strains } \\
\text { resistant }\end{array}$} & \multicolumn{4}{|c|}{$\begin{array}{l}\text { Strains for which minimum bactericidal } \\
\text { concentration of chlorhexidine was }\end{array}$} \\
\hline & & & & \multicolumn{2}{|c|}{1 in 20,000 or less } & \multicolumn{2}{|c|}{ more than 1 in 20,000} \\
\hline & & & & Number & Per cent. & Number & Per cent. \\
\hline $\begin{array}{l}\text { In-patients } \\
\text { O.P. and G.P. }{ }^{*} \\
\text { All sources }\end{array}$ & $\begin{array}{l}\text { Normal } \\
\text { Normal } \\
\text { Normal }\end{array}$ & $\begin{array}{l}0-3 \\
0-3 \\
0-3\end{array}$ & $\begin{array}{l}40 \\
31 \\
71\end{array}$ & $\begin{array}{l}24 \\
22 \\
46\end{array}$ & $\begin{array}{l}60 \cdot 0 \\
71 \cdot 0 \\
64 \cdot 8\end{array}$ & $\begin{array}{r}16 \\
9 \\
25\end{array}$ & $\begin{array}{l}40 \cdot 0 \\
29 \cdot 0 \\
35 \cdot 2\end{array}$ \\
\hline $\begin{array}{l}\text { In-patients } \\
\text { O.P. and G.P. : } \\
\text { All sources }\end{array}$ & $\begin{array}{l}\text { Normal } \\
\text { Normal } \\
\text { Normal }\end{array}$ & $\begin{array}{l}4-6 \\
4-6 \\
4-6\end{array}$ & $\begin{array}{l}34 \\
21 \\
55\end{array}$ & $\begin{array}{l}20 \\
13 \\
33\end{array}$ & $\begin{array}{l}58 \cdot 8 \\
61 \cdot 9 \\
60 \cdot 0\end{array}$ & $\begin{array}{r}14 \\
8 \\
22\end{array}$ & $\begin{array}{l}41 \cdot 2 \\
38 \cdot 1 \\
40 \cdot 0\end{array}$ \\
\hline $\begin{array}{l}\text { In-patients } \\
\text { O.P. and G.P. } \\
\text { All sources }\end{array}$ & $\begin{array}{l}\text { High } \\
\text { High } \\
\text { High }\end{array}$ & $\begin{array}{l}0-3 \\
0-3 \\
0-3\end{array}$ & $\begin{array}{r}64 \\
41 \\
105\end{array}$ & $\begin{array}{l}41 \\
34 \\
75\end{array}$ & $\begin{array}{l}64 \cdot 1 \\
66 \cdot 7 \\
65 \cdot 2\end{array}$ & $\begin{array}{l}23 \\
17 \\
40\end{array}$ & $\begin{array}{l}35 \cdot 9 \\
33 \cdot 3 \\
34 \cdot 8\end{array}$ \\
\hline $\begin{array}{l}\text { In-patients } \\
\text { O.P. and G.P. } \\
\text { All sources }\end{array}$ & $\begin{array}{l}\text { High } \\
\text { High } \\
\text { High }\end{array}$ & $\begin{array}{l}4-6 \\
4-6 \\
4-6\end{array}$ & $\begin{array}{r}10 \\
1 \\
11\end{array}$ & $\begin{array}{l}3 \\
1 \\
4\end{array}$ & $\begin{array}{c}30 \cdot 0 \\
100 \\
36 \cdot 4\end{array}$ & $\begin{array}{l}7 \\
0 \\
7\end{array}$ & $\begin{array}{r}70 \cdot 0 \\
0 \\
63 \cdot 6\end{array}$ \\
\hline
\end{tabular}

6 in the table. Kanamycin is also included since, although all but 1 of the 126 strains were sensitive to the high concentration, 61 appeared resistant when the normal one was used.

Table III shows that when disks containing normal concentrations of the drugs were used 71 of the 126 strains tested appeared resistant to 3 drugs or fewer, whilst 55 were resistant to 4 drugs or more. Of the 71 more drugsensitive strains 46 (64.8 per cent.) were killed by chlorhexidine 1 in 20,000 or less. The degree of chlorhexidine-resistance of the 55 more drug-resistant strains differed little from that of the more drug-sensitive strains: 33 (60 per cent.) required a minimum bactericidal concentration (MBC) of 1 in 20,000 or less, whilst the remaining 22 strains had a MBC of more than 1 in 20,000 . 
There is thus no evidence of any association between drug-resistance and resistance to chlorhexidine.

When disks containing high concentrations of the drugs were used very few strains showed multiple drug-resistance. Of the 162 strains so tested, 115 appeared resistant to 3 drugs or fewer. Among these strains, those sensitive to the lower concentrations of chlorhexidine predominated, $75(65 \cdot 2$ per cent.) having a minimum bactericidal concentration of 1 in 20,000 or less.

Only 11 strains appeared resistant to 4-6 drugs, and 10 of these came from in-patients. Seven of the latter required the higher concentration of chlorhexidine to produce a bactericidal effect.

All one can say is that so far as these few strains are concerned, there is a suggestion of an association between drug-resistance and resistance to chlorhexidine.

\section{Discussion}

In the present series, proteus strains of four species did not show a degree of chlorhexidine-resistance likely to be of practical importance, since no strain survived a concentration of 1 in 5000, and only 5 (all Pr. mirabilis) a concentration of 1 in 10,000. These concentrations are, however, close to some that may be used in practice. In the course of a recent study dealing with the prevention of post-operative urinary tract infections, Gillespie et al. (1967) tested 13 strains of Pr. mirabilis against chlorhexidine, and found that 4 of the strains had a minimum inhibitory concentration (MIC) of 1 in 4000, and 2 a MIC of 1 in 2000. Lubsen et al. (1961) also found that of 19 strains of Pr. mirabilis, 2 had a minimum bactericidal concentration of 1 in 2000 chlorhexidine, and 9 of 1 in 4000 .

It is tempting to speculate that resistant strains occur more frequently in an environment where the antiseptic is freely used. If so they would be more frequently found in hospital in-patients, and perhaps would also be associated with multiple drug-resistance, since the supposition is often made that multiple drug-resistant strains are more likely to originate in hospital. No support was found however for this hypothesis. The proportion of chlorhexidine-resistant strains was about the same for hospital in-patients and out-patients.

As regards the relation between drug-resistance and chlorhexidineresistance among Pr. mirabilis strains, the case for an association between the two is, at best, " not proven".

A point of interest is the marked sensitivity of Pr. rettgeri to chlorhexidine, which is surprising in view of the findings of Lubsen et al. They tested 15 strains, and found that the minimum bactericidal concentration for 1 strain was 1 in 1000 , for 3 strains 1 in 4000 , for 7 strains 1 in 8000 , and for 4 strains 1 in 16,000 . Their methods were not precisely the same as mine, and this might affect the absolute figures, but it is more difficult to see why the relative results between species should be affected. However, in any kind of survey without typing, it is not possible to say how many times the same strain is repeated in a collection.

Finally, it is noteworthy that species of the genus Proteus show marked 
differences in resistance to chlorhexidine. Species differences in resistance to antibiotics are, of course, well known. Commercial producers of antisepticsand indeed, sometimes of antibiotics-are apt to assess the activity of their product against this genus in terms of "Proteus species" or "Pr. vulgaris". In view of possible species differences in this respect, the former assessment is unhelpful, and the latter may be misleading, since Pr. mirabilis, and not $P r$. vulgaris, is the common cause of human infections.

\section{SUMMARY}

The action of the antiseptic chlorhexidine has been tested against 205 strains of the genus Proteus. No strain was found to survive, under the conditions of the test, a concentration of 1 in 5000. The four species of the genus, however, varied in sensitivity. In general, Pr. mirabilis was the most resistant; Pr. rettgeri and Pr. morganii were the most sensitive; Pr. vulgaris tended to be less resistant than Pr. mirabilis and more so than Pr. rettgeri and Pr. morganii.

The same strains were also tested against a number of chemotherapeutic drugs. Evidence that resistance to chlorhexidine among Pr. mirabilis strains was associated with multiple drug-resistance could not be established.

\section{REFERENCES}

Beeuwkes, H. . . . . . . . . . 1961. Lancet, $2,53$.

Davies, G. E., Francis, J., Martin, 1954. Br.J. Pharmac. Chemother., 9, 192.

A. R., Rose, F. L., ANd Swain, G.

Dutton, A. A. C., ANd Ralston, Mary 1957. Lancet, 1, 115.

EDWARDS, P. R., AND EwING, W. H. 1962. Identification of Enterobacteriaceae, 2nd

Falkow, S. . . . . . . . . . 1958. Amer. J. Clin. Path., 29, 598.

Gillespie, W. A., Lennon, G. G., 1967. Br. Med. J., 3, 90.

Linton, K. B., AND PhipPEN, G.

AUDREY

KIPPAX, P. W. . . . . . . . . 1957. J. Clin. Path., 10, 211.

LAWrence, C. A. . . . . . . . . 1960. J. Amer. Pharm. Assoc., 49, 731.

Lubsen, N., Boissevain, W., AND Fass, 1961. Lancet, 2, 53.

HANNA

Milner, P. F. . . . . . . . . 1963. J. Clin. Path., 16, 39.

MøLler, V. . . . . . . . . . 1955. Acta path. microbiol. scand., 36, 158. 